\title{
Bilateral Anterior Opercular Syndrome With Partial Kluver-Bucy Syndrome in a Stroke Patient: A Case Report
}

\author{
Ah-Ra Cho, MD ${ }^{1}$, Young-Ho Lim, MD¹, Sae-Hoon Chung, MD', \\ Eun-Hi Choi, MD, PhD' ${ }^{1}$ Jong Youb Lim, $\mathrm{MD}^{1,2}$
}

\begin{abstract}
${ }^{1}$ Department of Rehabilitation Medicine, Hallym University Chuncheon Sacred Heart Hospital, Hallym University College of Medicine, Chuncheon; ${ }^{2}$ Department of Rehabilitation Medicine, Eulji University Hospital, Daejeon, Korea
\end{abstract}

Bilateral anterior opercular syndrome and partial Kluver-Bucy syndrome are associated with bilateral middle cerebral artery lesions. The combination of these two syndromes has only been reported in a child with limbic encephalitis. In this case, a 44-year-old woman with bilateral middle cerebral artery infarction, which occurred 2 years prior, could walk independently. However, she showed automatic-voluntary dissociation and anarthria with preserved writing skills. She also presented hypersexuality, hypermetamorphosis, and memory disturbances. Here, we report a case of an adult stroke patient who suffered from bilateral anterior opercular syndrome accompanied by partial Kluver-Bucy syndrome.

Keywords Bilateral anterior opercular syndrome, Kluver-Bucy syndrome, Stroke

\section{INTRODUCTION}

Bilateral lesions of the opercular cortex cause bilateral anterior opercular syndrome, also known as Foix-Chavany-Marie syndrome [1]. Two main features are evident in this syndrome: one is facio-labio-pharyngo-glosso-masticatory paralysis, such as central-type facial palsy and difficulty opening the mouth or swallowing; the other is automatic-voluntary dissociation, expressed as preserved facial muscle movement and an opened mouth during yawning and laughing $[1,2]$.

Kluver-Bucy syndrome is related to the dysfunction of bilateral temporal lobes. Neurological symptoms include hyperorality, hypersexuality, hypermetamorphosis, memory disorders, placidity, and bulimia $[3,4]$. A patient with classic Kluver-Bucy syndrome exhibits all of these features, whereas a patient with partial Kluver-Bucy syndrome exhibits three or more of the listed features [4].

Bilateral anterior opercular syndrome and partial Kluver-Bucy syndrome are associated with bilateral middle

Received June 18, 2015; Accepted August 21, 2015

Corresponding author: Jong Youb Lim

Department of Rehabilitation Medicine, Eulji University Hospital, 95 Dunsanseo-ro, Seo-gu, Daejeon 35233, Korea. Tel: +82-42-611-3631, Fax: +82-42611-3633, E-mail: jylimmd@eulji.ac.kr

ORCID: Ah-Ra Cho (http://orcid.org/0000-0003-3533-2243); Young-Ho Lim (http://orcid.org/0000-0002-4446-3854); Sae-Hoon Chung (http://orcid. org/0000-0002-7861-9503); Eun-Hi Choi (http://orcid.org/0000-0002-7345-6952); Jong Youb Lim (http://orcid.org/0000-0001-9100-4864).

(c) This is an open-access article distributed under the terms of the Creative Commons Attribution Non-Commercial License (http://creativecommons.org/ licenses/by-nc/4.0) which permits unrestricted noncommercial use, distribution, and reproduction in any medium, provided the original work is properly cited. Copyright $\odot 2016$ by Korean Academy of Rehabilitation Medicine 
cerebral artery lesions. However, these syndromes are rare $[1,3]$ and the combination of these two syndromes was only reported in a child with limbic encephalitis [5]. In this case report, the authors describe an adult stroke patient who suffered from bilateral anterior opercular syndrome accompanied by partial Kluver-Bucy syndrome.
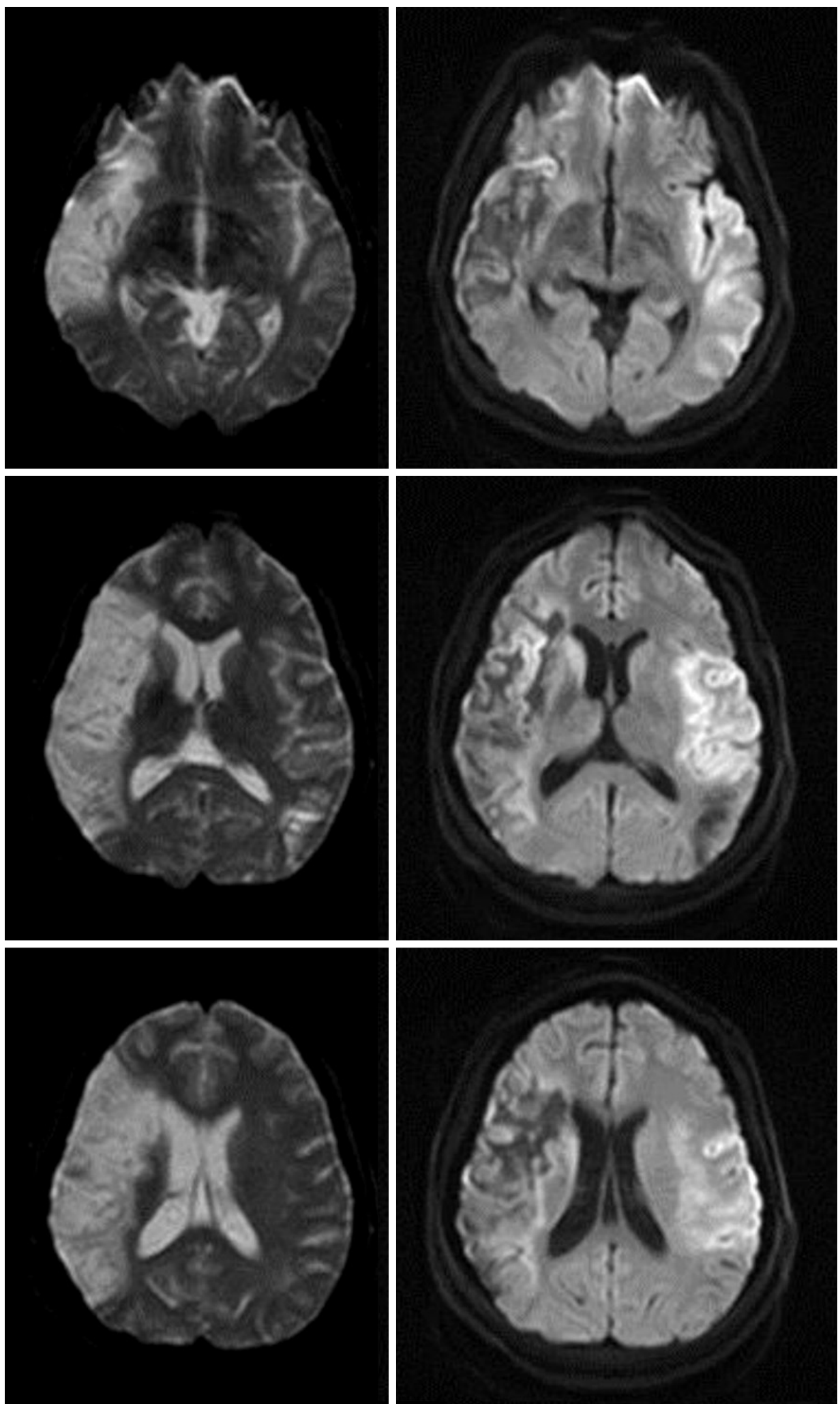

Fig. 1. Brain diffusion magnetic resonance imaging with $\mathrm{b}=0$ (left) and $b=1,000$ (right) showed subacute right middle cerebral artery infarction (left) and acute left middle cerebral artery infarction (right), including the bilateral anterior operculum. 


\section{CASE REPORT}

A 42-year-old woman with dizziness was admitted to the hospital and diagnosed with right middle cerebral artery infarction after brain magnetic resonance imaging (MRI). Echocardiography revealed a patent foramen ovale and she was discharged with warfarin medication. The subject showed no sequelae, such as motor weakness or cognitive dysfunction. After a month, she developed right hemiplegia and was diagnosed with left middle cerebral artery infarction upon second brain MRI (Fig. 1). After thrombolysis, hemiplegia was improved and she could walk independently. However, she showed anarthria, inability to open the mouth, and violent behaviors. She was admitted to a long-term care hospital for 2 years and fed with a nasogastric tube. After that time, she was admitted to our rehabilitation department for dysphagia management.

Her mental status was alert. She communicated with others by written message and exchanged text messages with her family; however, she did not speak. She could blink both eyes spontaneously and her pupil light reflexes were normal; however, she could not close her eyes on command. Following the order to open her mouth, she would try, but her mouth would open only $0.5 \mathrm{~cm}$ (Fig. 2). On the other hand, her natural mouth opening was observed at $7 \mathrm{~cm}$ when she was yawning or laughing. She was evaluated as anarthria, because she could make "Mmm" sounds only and she showed no voluntary movement of the tongue, lips, and jaws. She could not remember events that had just occurred well. Her Mini-Mental Status Examination score was 22/30. Three-item registration was possible, however, memory recall was decreased at $0 / 3$, and attention and calculation were decreased at
$2 / 5$. According to a videofluoroscopic swallowing study, there were no bolus formations and no translation to the pharyngeal phase due to decreased tongue tipping.

Using a bundle of tongue depressors, she received mouth opening training and was asked to imitate brushing her teeth while looking at her reflection in the mirror. After 4 weeks, she could open her mouth $3 \mathrm{~cm}$ voluntarily (Fig. 2). She was trained in semisolid swallowing while watching herself in the mirror for the subsequent 2 weeks. Her mouth opening increased to $4 \mathrm{~cm}$ and she could independently consume half bottle of yogurt per oral for 10 minutes (Fig. 3).

Occasionally, she showed irritable behaviors. Sometimes she went into the ward for men and rubbed the abdomens of some men whom she did not know. During

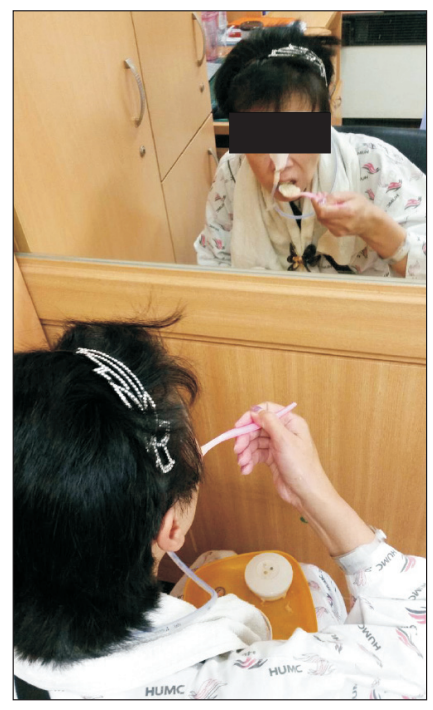

Fig. 3. The patient was trained in opening her mouth and semisolid swallowing in front of the mirror.
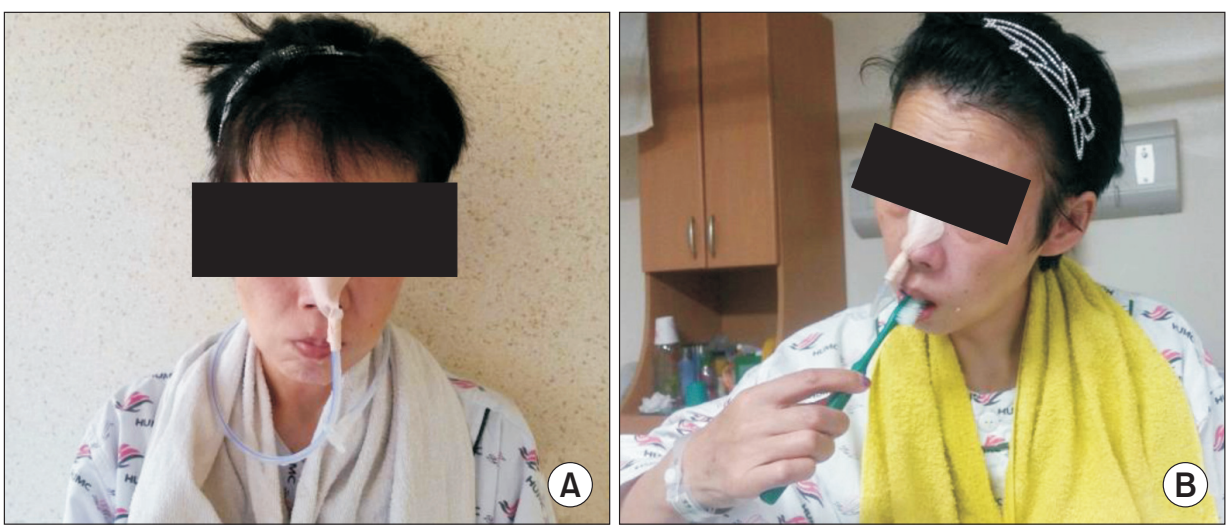

Fig. 2. On the administration day, she tried to open her mouth and she could not (A). After 4 weeks of training, the patient could brush her teeth by herself (B). 
doctors' rounds, she frequently reached out her hand and tried to grasp the hands of the doctors, even though she was requested not to do so. Her irritable behaviors and sexual episodes decreased after quetiapine and sodium valproate administration.

\section{DISCUSSION}

This patient showed classic features of bilateral anterior opercular syndrome, which usually results from bilateral middle cerebral artery stroke [6]. This syndrome is characterized by the loss of the voluntary movement of the facial and tongue muscles with a preserved reflex movement in these muscles, anarthria with preserved writing skills, and the absence of limb weakness. Automatic-voluntary dissociation occurs because the voluntary control of facial and tongue muscles is supplied by the primary motor cortex and the pyramidal tract, whereas the extrapyramidal tract, the thalamus, and the hypothalamus supply emotional and spontaneous control $[7,8]$.

This patient could not open her mouth voluntarily; however, she could open the mouth during yawning and laughing. After 6 weeks of training, she showed improvement in mouth opening and swallowing, however, anarthria was not improved. This is because more voluntary control and longer loop reflexes are involved in speech production than in swallowing $[7,9]$. Generally, bilateral anterior opercular syndrome patients appear to have poor prognosis for recovery of speech and may need additional communication devices while they develop the ability to eat by mouth independently with dietary viscosity adjustments [7].

As voluntary movement could be facilitated with cues, mouth opening training with a bundle of tongue depressors was reported to be effective in this syndrome [9]. After the demonstration of mouth opening and swallowing by an occupational therapist, the patient was trained to swallow while watching herself in the mirror. Action observation and mental imagery are known to promote motor recovery and the mirror neuron located in the premotor cortex and the intraparietal lobe plays a central role [10].

Some reports concerning bilateral anterior opercular syndrome present mouth opening and swallowing improvements during first 6 months after symptom onset, while others report persistent disability. There were no reports concerning dysphagia rehabilitation in the chronic phase $[1,6,7,9]$. The recovery course could be the result of spontaneous recovery; however, this patient showed improvement with this specific rehabilitation, which was started 2 years after a stroke. Therefore, intensive rehabilitation for persistent dysphagia of the bilateral anterior opercular syndrome patient whose early rehabilitation was not successful is meaningful. The approach documented in this report can be helpful in planning for the treatment of bilateral anterior opercular syndrome.

The subject also exhibited features of Kluver-Bucy syndrome, which is primarily related to the bilateral temporal lobe [3]. Partial Kluver-Bucy syndrome presents at least three features of the classic symptoms [4]. In this case, the patient presented with hypersexuality, hypermetamorphosis, and memory disturbances. She showed hypersexuality in that she entered the ward for men and rubbed the abdomens of some men who were strangers to her. She did not rub the abdomens of any women who shared the ward with her, nor did she enter the ward for other women. Hypermetamorphosis, a tendency to attend to every visual stimulus with grasping [4], was displayed during doctors' rounds. She is a high school graduate and her memory disturbances were unrelated to her educational level.

Previous reports showed the beneficial effects of carbamazepine and antipsychotics in the Kluver-Bucy syndrome treatment [3-5]. This patient had partial improvement with quetiapine as an atypical antipsychotic in her impulsive behavior and sexual episodes and a greater improvement was observed when valproate was added to her medication regimen. Early consideration of active pharmacologic treatment for violent behaviors, which can hinder the rehabilitation, is needed in the various courses of Kluver-Bucy syndrome [3].

Although bilateral anterior opercular syndrome and partial Kluver-Bucy syndrome share bilateral middle cerebral artery lesions as a common etiology, the occurrence of the combination of these two rare syndromes is very uncommon. The combination of these syndromes has only been reported once and was concerning a child with limbic encephalitis [5] who showed hyperorality instead of hypermetamorphosis and the treatment was carried out with medication only and resulted in partial improvement. To the best of the authors' knowledge, this is a first case that has occurred in an adult and a stroke 
patient with bilateral anterior opercular syndrome and partial Kluver-Bucy syndrome.

\section{CONFLICT OF INTEREST}

No potential conflict of interest relevant to this article was reported.

\section{REFERENCES}

1. Lekhjung T, Raju P. Opercular syndrome: case reports and review of literature. Neurol Asia 2010;15:145-52.

2. Weller M. Anterior opercular cortex lesions cause dissociated lower cranial nerve palsies and anarthria but no aphasia: Foix-Chavany-Marie syndrome and "automatic voluntary dissociation" revisited. J Neurol 1993;240:199-208.

3. Chou CL, Lin YJ, Sheu YL, Lin CJ, Hseuh IH. Persistent Kluver-Bucy syndrome after bilateral temporal lobe infarction. Acta Neurol Taiwan 2008;17:199-202.

4. Bhat PS, Pardal PK, Das RC. Partial Kluver-Bucy syn- drome as a delayed manifestation of head injury. Ind Psychiatry J 2009;18:117-8.

5. Kar SK, Jaiswal A, Panda AK. A case report of partial Kluver-Bucy syndrome with anterior opercular syndrome in childhood: a sequel of limbic encephalitis. J Indian Assoc Child Adolesc Ment Health 2013;9:80-8.

6. Nowak DA, Griebl G, Dabitz R, Ochs G. Bilateral anterior opercular (Foix-Chavany-Marie) syndrome. J Clin Neurosci 2010;17:1441-2.

7. Mao CC, Coull BM, Golper LA, Rau MT. Anterior operculum syndrome. Neurology 1989;39:1169-72.

8. Milanlioglu A, Aydin MN, Gokgul A, Hamamci M, Erkuzu MA, Tombul T. Ischemic bilateral opercular syndrome. Case Rep Med 2013;2013:513572.

9. Kim DE, Lee YS, Park SH, Park KI, Cho JY, Kim SS, et al. A case of bilateral anterior opercular syndrome: Foix-Chavany-Marie syndrome. J Korean Neurol Assoc 2000; 18:450-3.

10. Mulder T. Motor imagery and action observation: cognitive tools for rehabilitation. J Neural Transm (Vienna) 2007;114:1265-78. 